\section{Selena Millares}

Profesora de literatura hispanoamericana en la Universidad Autónoma de Madrid, es autora de los libros La génesis poética de Pablo Neruda (1992) y La maldición de Sheherezade. Actualidad de las letras centroamericanas (1997); coautora de una Historia de la literatura hispanoamericana (1996) y editora de varias obras contemporáneas. Ha publicado artículos en torno a temas tan diversos como el modernismo visionario, la vanguardia poética o las Américas de Calibán, y sobre autores como Pablo Neruda, Gabriela Mistral, Gonzalo Rojas, Alejo Carpentier, Virgilio Piñera y Miguel Ángel Asturias.

Simbolismo y modernismo: lecturas nerudianas

SELENA MILLARES

\title{
SIMBOLISMO Y MODERNISMO: LECTURAS NERUDIANAS
}

\author{
SELENA MILLARES
}

Romanticismo, simbolismo, modernismo: confabulación poética de vasos comunicantes que determina y signa la poesía moderna desde la más saludable irreverencia, desde una insurgencia necesaria que, minuciosa y persistente, se ocupa de derrumbar cada uno de los dogmas, tabúes y leyes que limitaban sus anhelos. Al fin convocados, entran en la literatura como un torrente impetuoso los fantasmas que antes tan sólo se atrevían a rondarla: los de la fealdad, que daba sentido a la belleza; los del cuerpo, que daban la réplica al espíritu; los de la miseria, que inevitable latía en la grandeza. Llega, en fin, toda aquella belleza maldita que puebla el imaginario del hombre a pesar de las normas de la mesura y el buen gusto, en una corriente impetuosa e imparable que va del matrimonio del cielo y el infierno de William Blake a las proclamas más iconoclastas y decidoras de las vanguardias, y entre ellas, a esa nerudiana reivindicación de una poética de la impureza que todavía no ha perdido vigencia, y que nos hablaba de una poesía «gastada como por un ácido por los deberes de la mano, penetrada por el sudor y el humo, oliente a orina y a azucena» (Neruda, 2001: 381).

Fin, entonces, de las servidumbres morales y estéticas, de los contratos miméticos y las exigencias didácticas: los nuevos poetas enarbolan las conquistas de los grandes patriarcas -también heresiarcas- para explorar sin límites lo plutónico, lo onírico y también lo erótico sin atender al anatema. La libertad se instituye en nuevo culto, que ve en el mundo físico, como lo enunciara Saint-Pol-Roux, «un vase empli de métaphysique» (Michaud, 1947:
762). Para los poetas simbolistas, el arte ha de adivinar o descifrar las correspondencias del mundo externo con el paisaje interior del propio autor. El hermetismo será a menudo la consecuencia directa de esa actitud, el mismo que ha de componer hitos de la vanguardia tan relevantes como ese «apocalipsis sin dios» que, en términos de Amado Alonso, define a Residencia en la tierra. Sus raíces se remontan, entonces, a Baudelaire, Rimbaud, Verlaine y Mallarmé, entre otros que, para C. M. Bowra, «intentaron manifestar una experiencia sobrenatural en el lenguaje de las cosas visibles, y en los que casi cada palabra es un símbolo, ya que está utilizada no según su uso corriente, sino por la asociación que evoca con una realidad más allá de los sentidos» (Bowra, 1972: 14). Su versión hispánica, el modernismo, incide en las mismas estrategias, como se desprende de las declaraciones de uno de sus más insignes representantes, Julio Herrera y Reissig, tan caro a Neruda, que declaraba en 1889: «Este es el siglo de la libertad del arte, mariposa de alas brillantes que ha roto su crisálida retórica y se ha elevado por los aires, ostentando todos los matices del gusto». Más tarde afirmará: «En el imperio de la Quimera, ser visionario es ser real, es ver el fondo» (Herrera y Reissig, 1978: 278, 282).

En definitiva, el salto cualitativo que va del romanticismo a las nuevas estéticas se sustenta en una serie de estrategias discursivas de perfil neto, que poblarán fértiles la producción de vanguardia y posvanguardia. Entre ellas destaca la desubjetivación -esa desaparición elocutoria del poeta propugnada por $\mathrm{Ma}$ llarmé-, que lleva a reducir el vocabulario 
afectivo: «llueve en mi corazón» (Verlaine, 1984: 178), «está cansado y triste mi corazón, y llora» (Henri de Régnier, en Díez-Canedo, 1945: 315), «sobre mi corazón llueven frías corolas» (Neruda, 1999a:197), «el llanto cae en pétalos» (Neruda, 1999a:299); «Hay cementerios solos, / tumbas llenas de huesos sin sonido, / el corazón pasando un túnel / oscuro, oscuro, oscuro...» (Neruda, 1999a:301).

$\mathrm{El}$ arte de las correspondencias se proyecta en una explotación intensa de esas sinestesias de las que Proust extrajo su concepto de memoria involuntaria: de ahí las grises indolencias de Rimbaud (1986: 334), los amarillos pliegues del pensamiento de Mallarmé (1982: 65), los extremos de Herrera y Reissig -palomas lilas, lepra azul de idealismo... (1978: 34, 46) -, y, ya en Neruda, la sed amarilla de la tierra (2000: 187), el ruido escarlata de las ametralladoras (2000: 413) o la medusa violeta de la envidia (1999b:1286). Las interferencias semánticas se multiplican, especialmente entre lo animado y lo inanimado, lo abstracto y lo concreto, lo material y lo inmaterial, de modo que el discurso se hace ambiguo, sugerente, oblicuo, desde las hipálages, metonimias y símbolos, con una iconografía específica que se fundamenta en ámbitos crepusculares y aguas de muerte. Los ejemplos nerudianos se harán innumerables: «todo se cubre de un sabor mortal» (1999a: 312), «la luna tiene olor a uvas blancas, a miel, a limones caídos» (1999a: 1072), «olor a sombra, a estrella / a escama de la luna» (1999b: 1110). Por otra parte, el poeta es visionario y medium, sacerdote de una nueva religión, como lo explica Rimbaud:

El poeta se hace vidente mediante un largo, inmenso y razonado desarrollo de todos los sentidos. Todas las formas de amor, de sufrimiento, de locura; busca por sí mismo, apura en él todos los venenos y se queda con su quintaesencia. Tortura inefable en la que necesita toda la fe, toda la fuerza sobrehumana, y por la que se convierte en el gran enfermo, el gran criminal, el gran maldito - ¡Y el sabio Supremo!- pues así alcanza lo desconocido (Todó, 1987: 69).

El gesto del vidente hallará una fértil proyección en el motivo del viaje inmóvil, poetizado ya por William Blake en «El viajero mental», que Neruda tradujo, y se hacen eco de esa estrategia Baudelaire con «El bello navío» o «Invitación al viaje», Rimbaud con su «barco ebrio», Mallarmé con «Un golpe de dados...» y el propio Neruda con Tentativa del hombre infinito, o con el poema 9 de Veinte poemas de amor, así como una amplia serie de pasajes de su itinerario creador.

Algunos palimpsestos específicos podrían servir para testimoniar, de un modo explícito, la enorme importancia de esas lecturas: la ardiente paciencia de Rimbaud, los ciegos y los amantes de Maeterlinck, el naufragio enigmático de Mallarmé... El joven Neruda, estudiante de francés inmerso en la bohemia capitalina, devoraba con fruición a sus maestros para transmutarlos en parte de su propia savia poética. Basten unos pocos ejemplos como muestra. En uno de sus primeros poemas, «Luna», Neruda recrea el momento de su propio nacimiento, que conlleva la muerte de su madre:

Cuando nací mi madre se moría con una santidad de ánima en pena.

Era su cuerpo transparente. Ella tenía

bajo la carne un luminar de estrellas.

Ella murió. Y nací.

Por eso llevo

un invisible río entre las venas, un invencible canto de crepúsculo que me enciende la risa y me la hiela

[...] Esta luna amarilla de mi vida me hace ser un retoño de la muerte (Neruda, 2001: 205).

La metáfora con que se representa a la muerte fluye exacta desde un poema de Baudelaire: «Y, cuando respiramos, la Muerte a nuestros pulmones / desciende, río invisible, con apagados lamentos» (Baudelaire, 1977: 28). La identificación nerudiana de la luna con la muerte sigue, naturalmente, un topos literario clásico. Sin embargo, aparece aquí aliada con las propuestas de Baudelaire, quien en «Las bondades de la luna» presenta al astro y sus poderes vampirizando a una niña pequeña con su estigma de melancolía y muerte. Después, Neruda reitera el gesto en «Enfermedades en mi casa", de Residencia en la tierra, dedicado a su hija: «cada día de luna / sube sangre de niña hacia las hojas manchadas por la luna» (1999a: 316). El río funesto, la luna, la muerte, se confabulan de nuevo en esta imagen de neta raigambre simbolista.

Los palimpsestos no son aislados; puede recordarse, igualmente, la identificación de la muerte con un capitán, presente en «El viaje» de Baudelaire («iOh muerte, viejo capitán, ya

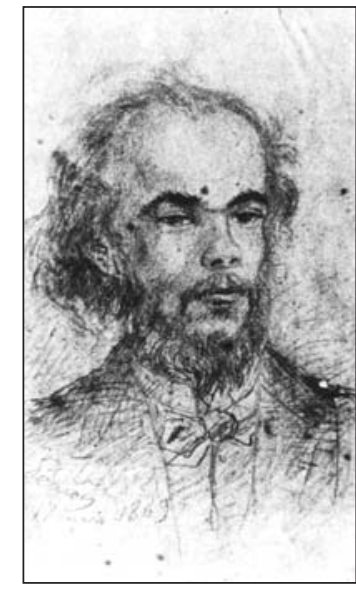

Dibujo de Verlaine por Carrière.
Simbolismo y modernismo: lecturas nerudianas

SELENA MILLARES 


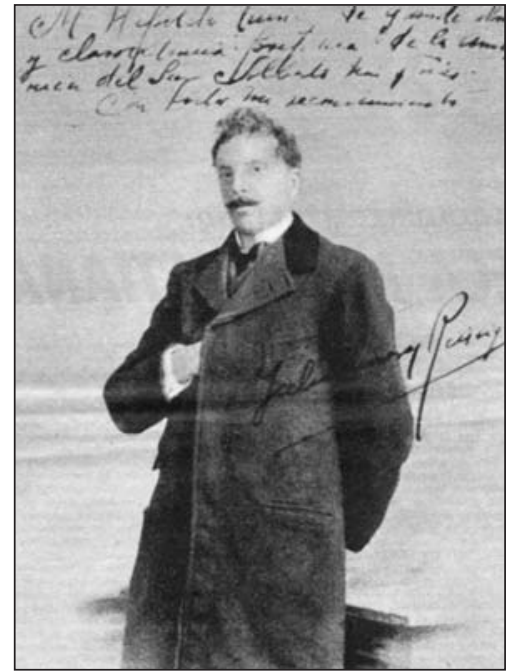

es hora!», 1977: 372), que vuelve en Residencia: «Arranco de mi corazón al capitán del infierno»; "oh Capitán, en nuestra hora de reparto / abre los mudos cerrojos y espérame» (1999a: 259, 268). Esta simbiosis explicaría una variante del mismo poemario:

La muerte está en los catres:

en los colchones lentos, en las frazadas negras vive tendida, y de repente sopla:

sopla un sonido oscuro que hincha sábanas, y hay camas navegando a un puerto en donde está esperando, vestida de almirante (1999a: 302).

Julio Herrera y Reissig.

Simbolismo y modernismo: lecturas nerudianas

SELENA MILLARES
Un último ejemplo podría ser el del jugador siniestro que, en la escritura baudelairiana, representa al tiempo que gana siempre y sin trampas:

La bella sota de corazón y la dama de pique charlan siniestramente de sus amores difuntos

(«Spleen», Baudelaire, 1977: 198)

¡Acuérdate que el tiempo es un jugador ávido que gana sin trampear, en todo lance! ¡Es la ley!

(«El reloj», Baudelaire, 1977: 228)

Neruda reitera la imagen en el poema «A la baraja», de Memorial de Isla Negra y la imagen tradicional del combate con la muerte, siempre vencedora, se transmuta por la del juego de naipes que decide un compás de espera frente a lo inexorable:

Sólo seis oros,

siete

copas, tengo.

Y una ventana de agua.

Una sota ondulante, y un caballo marino con espada.

[...]Ahora que me digan qué juego, qué adelanto, qué pongo, qué retiro, si naipes navegantes, si solitarias copas, si la reina o la espada. Que alguien mire y me diga, Mire el juego del tiempo,
Las horas de la vida,

Las cartas del silencio,

La sombra y sus designios,

$Y$ me diga qué juego

Para seguir perdiendo (Neruda, 1999b: 1294-1295)

En el poema de Estravagario «Baraja» vuelve la imagen, en clave de humor visionario, y también en «La insepulta de Paita», de Cantos ceremoniales, donde alumbra una imagen oscura: «la baraja del incendio: / en el juego de vida o muerte» (Neruda, 1999b: 1031).

En este flujo de la intertextualidad, el modernismo ha de aportar, igualmente, innumerables hilos a la trama plural y fértil de la voz nerudiana, desde voces veneradas como las de Herrera y Reissig o López Velarde, y también Silva o Martí, pero muy especialmente la de Rubén Darío, así como el posmodernista uruguayo Carlos Sabat Ercasty; ambos, reconocidos por Neruda en reiteradas ocasiones, habrán de ser protagonistas de su recorrido poético en distintas dimensiones.

El caso del primero ha sido tempranamente señalado, además, en el estudio ya clásico de Amado Alonso -Poesía y estilo de Pablo $\mathrm{Ne}$ ruda-: ahí se explica, a partir de un poema de Darío, la metáfora que rige el poema residenciario "Barcarola», que él vincula con el soneto dariano «Caracol», dedicado a Antonio Machado: «...y oigo un rumor de olas y un incógnito acento, / y un profundo oleaje y un misterioso viento... / (El caracol la forma tiene de un corazón)» (Darío, 1983: 130). De ahí provendrá la identificación nerudiana del corazón con el caracol, que sonará con un llanto lúgubre, para hablarnos, con ese ulular fúnebre, de la desolación afectiva del poeta:

Si solamente me tocaras el corazón, si solamente pusieras tu boca en mi corazón, tu fina boca, tus dientes, si pusieras tu lengua como una flecha roja allí donde mi corazón polvoriento golpea, si soplaras en mi corazón, cerca del mar, llorando, sonaría con un ruido oscuro, con sonido de ruedas de [tren con sueño,

como aguas vacilantes, como el otoño en hojas, como sangre [...] o bocinas de puerto triste... (Neruda, 1999a: 303)

Más complejo es el itinerario de otra imagen de Cantos de vida y esperanza, concre- 
tamente de uno de sus poemas fundamentales, «Lo fatal», cuyo final queda inevitablemente grabado en el lector, casi como una cicatriz:

Y el espanto seguro de estar mañana muerto, y sufrir por la vida y por la sombra y por

lo que no conocemos y apenas sospechamos, y la carne que tienta con sus frescos racimos, y la tumba que aguarda con sus fúnebres ramos, ¡y no saber a dónde vamos, ni de dónde venimos!... (Darío, 1983: 148).

La nómina de pulsos signados por esta imagen es extensa, y el Neruda último habrá de rendirle igualmente el debido homenaje. Ya antes lo hicieron otros "ríos del canto»; Vicente Aleixandre, en Historia del corazón, de 1954, cita a Darío como epígrafe de un poema amoroso, para luego glosarlo:

Sabemos a dónde vamos y de dónde venimos. Entre dos oscuridades, un relámpago.

Y allí, en la súbita iluminación, un gesto, un único gesto, Una mueca más bien, iluminada por una luz de estertor (Aleixandre, 1977: 183)

Por su parte, ya en los sesenta Octavio Paz contribuye a ese itinerario dialógico en el poema «Certeza», de Dias hábiles:

De una palabra a la otra

lo que digo se desvanece.

Yo sé que estoy vivo

entre dos paréntesis.

(Paz, 1990:329)

Mucho después, el nerudiano Libro de las preguntas (publicado póstumamente, en 1974) aporta una nueva glosa de los versos originarios de Darío, aunque tal vez pasados por el tamiz de Aleixandre, cuya respuesta invierte:

No será nuestra vida un túnel

Entre dos vagas claridades? (Neruda, 2000: 852)

Por lo demás, los reconocimientos y homenajes del poeta chileno al nicaragüense son frecuentes y apasionados. Los ecos darianos se sienten ya desde Crepusculario, no sólo en los temas y motivos -incluso en títulos («Helios») o imágenes (Pelleas es «lirio azul de un jardín imperial»)-, sino también en la corriente intertextual que establece «Pantheos» con «Lo fatal»:

Si quieres no nos digas de qué racimo somos no nos digas el cuándo, no nos digas el cómo pero dinos adónde nos llevará la muerte

(Neruda, 1999a: 112)

A pesar del consciente alejamien-

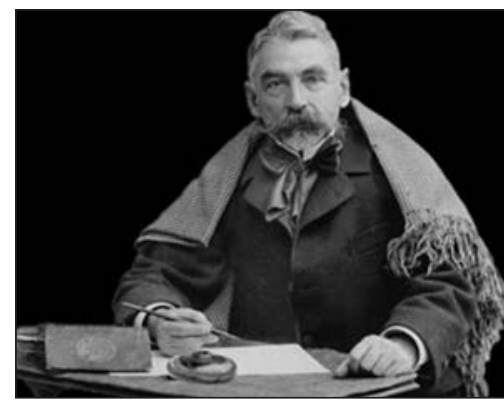

Stephane Mallarmè. to del modernismo, ya extemporáneo y ajeno a la forja de las nuevas andaduras, Darío seguirá presente como un río subterráneo, e incluso su «Pegaso» parece contribuir a diversos pasajes de Residencia y sus viajes visionarios sobre un caballo alado. Leemos en Darío: «domador del corcel de cascos de diamante / voy en un gran volar, con la aurora por guía / adelante en el vasto azur, siempre adelante» (Darío, 1983: 47); por su parte, Neruda reitera el viaje alado en «Caballo de los sueños»:

Qué día ha sobrevenido! Qué espesa luz de leche, compacta, digital, me favorece!

He oído relinchar su rojo caballo

desnudo, sin herraduras y radiante.

Atravieso con él sobre las iglesias, galopo los cuarteles desiertos de soldados

y un ejército impuro me persigue.

Sus ojos de eucaliptus roban sombra,

su cuerpo de campana galopa y golpea (Neruda, 1999a: 260)

Por otra parte, ya muchos han constatado la filiación del poema I de Cantos de vida y esperanza con el «Nuevo canto de amor a Stalingrado» de Tercera residencia:

Yo soy aquél que ayer no más decía

el verso azul y la canción profana,

en cuya noche un ruiseñor había

que era alondra de luz por la mañana (Darío, 1983: 25)

Yo escribí sobre el tiempo y sobre el agua,

describí el luto y su metal morado,

yo escribí sobre el cielo y la manzana, ahora escribo sobre Stalingrado (Neruda, 1999a: 396)

Ambos pasajes comparten la disposición formal en serventesios endecasilábicos, así como la temática, un modo de autobiografía poética. Más tarde, en las prosas de Viajes se suma Neruda a los homenajes que ya antes
Simbolismo y modernismo: lecturas nerudianas

SELENA MILLARES 


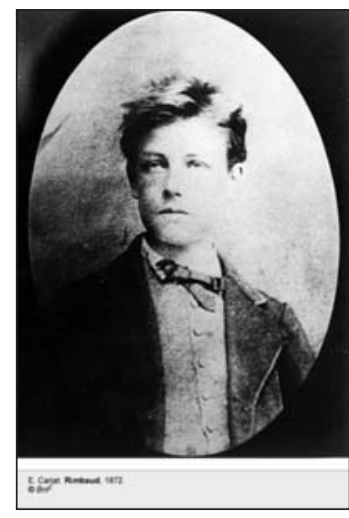

Arthur Rimbaud. alzaran insignes transgresores como Lugones o Girondo, que reconocieron en el maestro común al gran emancipador del idioma:

Rubén Darío, a quien pasaremos la mitad de la vida negando para comprender después que sin él no hablaríamos nuestra propia lengua, es decir, que sin él hablaríamos aún un lenguaje endurecido, acartonado y desabrido (Neruda, 2001: 454)

No puede evitarse, en este recorrido, recordar además el episodio que se le dedica en $L a$ Barcarola, de 1967, una semblanza biográfica -de inusitada configuración métrica en Neruda- donde lo imagina a su llegada a Valparaíso con los bolsillos llenos de cisnes y espejos, y también recrea su proceso hacia la cumbre, o su muerte en León, «lejos del amor, entregado al coñac de los filibusteros». La segunda sección se dedica a su gloria, y el extraordinario alquimista que fuera Neruda se transmuta momentáneamente para hacerse médium de su «padre poeta» y asumir su voz.

No termina aquí el tejido de este inmenso tapiz, donde se entrelazan, sin disonancias, voces poéticas aparentemente tan distantes. $\mathrm{Su}$ común vocación por el viaje órfico que inauguran los simbolistas, así como el tratamiento del tema erótico, habrán de constituir también una densa y magnética trama. Ambas temáticas se conjugan, en el caso dariano, en el «Coloquio de los centauros», con su naturaleza y sensualidad trascendente. Ahí el poeta cifra el enigma universal en boca de sus personajes míticos, en una «selva sagrada» donde amor y muerte se constituyen en motor de vida, con un panerotismo de clara raigambre whitmaniana. Neruda interpretará el mismo viaje imaginario, el mismo descenso hacia la fuente maternal y fértil, el «vientre de la tierra», en «El cazador de raíces» (Neruda, 1999b: 1252). El poeta reitera el viaje órfico en busca de la sustancia nutricia de la vida y la poesía. Se suceden los verba videndi propios de la experiencia visionaria («Ay yo vi...»), mientras avanza por una «espaciosa selva» hasta llegar al «útero de la tierra». Reaparece aquí la cosmovisión dariana en que se aúnan amor, vida y poesía en el vientre germinal de la Naturaleza, «selva devoradora» que acapara en su seno una sucesión de muertes y nacimientos. Todo se ha de resolver, finalmente, en el canto a la «madre materia, germen, tierra germinadora», como en el caso de Darío.
De la comunión panteísta y panerótica con la naturaleza-identificada con la madre fecunda y la mujer amada-que impulsa a ambos poetas, se hace eco Octavio Paz -en su esteladesde su ensayo «El caracol y la sirena»: «[...] el cuerpo de la mujer es el cuerpo del cosmos y amar es un acto de canibalismo sagrado. Pan sacramental, hostia terrestre. Comer ese pan es apropiarse de la sustancia vital [...] Su cosmología culmina en un misticismo erótico [...] Los actores de esta pasión no son personas sino fuerzas vitales [...] Esta vena de erotismo mágico se prolonga en varios grandes poetas hispanoamericanos, como Pablo Neruda» (Paz, 1980: 57). Merece atención el lema usado por Paz: el caracol y la sirena, aliados con el mar, funden su sonido para llevar al amor y a la muerte. Para Darío, el mar connota sensualidad, y conlleva resonancias mágicas y ambiguas, y también en Neruda, quien a menudo caracteriza a la amada con atributos marinos -por ejemplo, en numerosos poemas de Cien sonetos de amor-, $\mathrm{y}$ otras veces convierte al mar -como la noche, la lluvia, la tierra- en amante.

Igualmente, Darío, en el poema XVII de Cantos de vida y esperanza, presenta a la mujer como divinidad -«celeste carne»- pero también -en esa órbita whitmaniana que Neruda ha de compartir- la presenta como arcilla, madre-tierra: toda la existencia se resume en el «útero eterno» que vivifica el «sagrado semen». Neruda recurre al discurso de la liturgia herética en Crepusculario («Bésame, besadora, / ahora y en la hora / de nuestra muerte. Amén», 1999a: 116), pero después se detiene en las imágenes naturales, ya en la telurización de la amada, ya en la antropomorfización de la naturaleza:

Noche marina, estatua blanca y verde, te amo, duerme conmigo

[...] hermosa eres, amada, noche hermosa (Neruda,

[1999a: 803-804)

Otras cosas he visto, tal vez nada, países purpúreos, estuarios que traían del útero de la tierra, el olor seminal del origen (Neruda, 2000: 536)

[...] Andrómeda

y Sirio jugaron dejando sembrada de semen celeste la [noche del Sur
Simbolismo y modernismo: lecturas nerudianas

SELENA MILLARES 
Cabe, finalmente, recordar que también comparten ambos poetas los símbolos más comunes de la tradición amorosa, como las rosas, las palomas y las abejas, y no faltan en la poética nerudiana las apropiaciones más diversas del emblema modernista por antonomasia, el cisne, humillado en Residencia y su poética de la destrucción y el despojo (ahí es «cisne de fieltro», 1999a: 308), y después vivificado en Cien sonetos de amor, donde se recupera su belleza («deja que tus caderas impongan en el agua/ una medida nueva de cisne o de nenúfar/ y navegue tu estatua por el cristal eterno", 1999b: 861), y en Arte de pájaros se recoge el interrogante que dibuja la noble elegancia de su cuello. Pueden hallarse en Neruda incluso lo símbolos amatorios darianos que estudia Octavio Paz en el ensayo antes citado: la amada es caracola terrestre (1999a:180) y rosa mojada por sirenas y espumas (1999b: 910), amante que al mar galopando robé con puñal, ob sirena (1999b: 172).

En definitiva, la topografía del intercambio fértil de Neruda con sus «acreedores» poéticos se hace tan magnética como inabarcable. El poeta representaría en sus prosas esa relación como un inmenso taller imaginario «en el que todos trabajan y se ayudan, aunque no lo sepan ni lo crean». (Neruda, 2001: 1095), para confirmar esa certeza del idioma como un inmenso sistema de citas, tapiz imaginario que tejen incesantemente los muchos amanuenses que en el mundo han sido, que son, que permanecen.

\section{REFERENCIAS BIBLIOGRÁFICAS}

Aleixandre, Vicente, Historia del corazón, Madrid, Espasa-Calpe, 1977.

Alonso, Amado, Poesía y estilo de Pablo $\mathrm{Ne}$ ruda, Barcelona, EDHASA, 1979.

Baudelaire, Charles, Obra poética completa, Barcelona, Ediciones 29, 1977.
Borges, Jorge Luis, Obras completas, vol. II, Barcelona, Emecé, 1996.

Bowra, C. Maurice, La imaginación romántica, Madrid, Taurus, 1972.

Darío, Rubén, Cantos de vida y esperanza, Madrid, Espasa-Calpe, 1983.

Díez-Canedo, Enrique, La poesía francesa del Romanticismo al Superrealismo, Buenos Aires, Losada, 1945.

Herrera y Reissig, Julio, Poesía completa y prosa selecta, Caracas, Ayacucho, 1978.

Mallarmé, Stéphane, Poesía, Barcelona, Plaza \& Janés, 1982.

Michaud, Guy, Message poétique du Symbolisme, Paris, Nizet, 1947.

Neruda, Pablo, Obras completas, I. De Crepusculario a Las uvas y el viento. 19231954, Barcelona, Galaxia Gutenberg y Círculo de Lectores, 1999a.

- Obras completas, II. De Odas elementales a Memorial de Isla Negra. 1954-1964, Barcelona, Galaxia Gutenberg y Círculo de Lectores, 1999b.

- Obras completas, III. De Arte de pájaros a El mar y las campanas. 1966-1973, Barcelona, Galaxia Gutenberg y Círculo de Lectores, 2000.

- Obras completas, IV. Nerudiana dispersa I. 1915-1964, Barcelona, Galaxia Gutenberg y Círculo de Lectores, 2001.

- Obras completas, V. Nerudiana dispersa II. 1922-1973, Barcelona, Galaxia Gutenberg y Círculo de Lectores, 2002.

Paz, Octavio, Cuadrivio, México, Joaquín Mortiz, 1980.

- Obra poética (1935-1988), Barcelona, Seix Barral, 1990.

Rimbaud, Arthur, Poesía completa, Barcelona, Ediciones 29, 1986.

Todó, Lluís, El Simbolismo. El nacimiento de la poesía moderna, Barcelona, Montesinos, 1987.

Verlaine, Paul, Antología poética, Barcelona, Bosch, 1984.

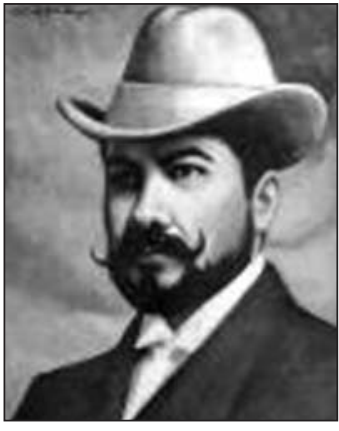

Rubén Darío.

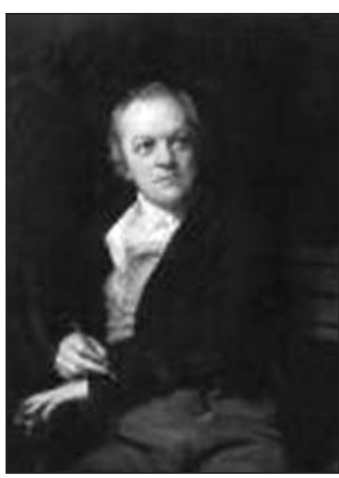

William Blake. 